\title{
Ergonomics Intervention to Reduce Work-Related Musculoskeletal Disorders in a Lead Mine
}

\author{
Mohammad Jahangiri, Seyyed Ali Moussavi Najarkola, ${ }^{2}$ Tahere Gholami, ${ }^{3}$ Hassan \\ Mohammadpour, ${ }^{4}$ Abbas Jahangiri, ${ }^{5}$ Ghasem Hesam, ${ }^{6}$ and Mahdi Jalali ${ }^{7, *}$
}

${ }^{1}$ Department of Occupational Hygiene, Collage of Health, Hamadan University of Medical Sciences, Hamadan, IR Iran

${ }^{2}$ Occupational and Environmental Health Research Center (OEHRC), Iranian Petroleum Industry Health Research Institute (IPIHRI), Petroleum Industry Health Organization (PIHO), Tehran, IR Iran

${ }^{3}$ Department of Hygiene, Fasa University of Medical Sciences, Fasa, IR Iran

4 Department of Hygiene, Fasa University of Medical Sciences, Fasa, IR Iran

5 Department of Industrial Engineering, Islamic Azad University, Arak Branch, Arak, IR Iran

6 Department of Industrial Engineering, Islamic Azad University, Arak Branch, Arak, IR Iran

${ }_{7}$ Department of Occupational Health, School of Public Health, Shahroud University of Medical Sciences, Shahroud, IR I

${ }^{*}$ Corresponding author: Mahdi Jalali, Department of Occupational Health, School of Public Health, Birjand University of Medical Sciences, Birjand, IR Iran. Tel: +98-9159292199, E-mail:m_jalali63_hse@yahoo.com

Received: May 27, 2015; Revised: July 20, 2015; Accepted: July 25, 2015

Background: Work-related musculoskeletal disorders (WMSDs) are one of the most important factors for occupational injuries and disabilities, with the back injuries being the most common work-related injuries in different industries in many developing countries. Objectives: The objectives of the present study were determination of the prevalence of WMSDs symptoms, identification of major risk factors associated with WMSDs symptoms and ergonomics interventions to reduce these disorders.

Patients and Methods: This follow-up and interventional study was carried out in a lead mine. Forty persons participated in this study. The Nordic musculoskeletal questionnaire was used to study the prevalence of WMSDs and the quick exposure check (QEC) method was used to assess the physical exposure to risks. Ultimately, data was analyzed using McNamar's and Cochran's tests by SPSS version 11 software. Results: The results revealed that the highest prevalence of musculoskeletal disorders was reported in lower back (57.5\%) and knees (50\%) during the 12 months prior to the study. After ergonomics interventions, significant reductions in WMSDs were observed at the time of follow-up. According to Cochran's test, significant differences between the pre, four and nine months after the intervention in lower back and knee were observed $(\mathrm{P}<0.005)$.

Conclusions: Consistent reductions were observed for all WMSDs disorders at the ninth month of the follow-up. It can be inferred that the use of practical and low-cost methods of engineering and administrative interventions together and monitoring the proper implementation of these interventions during a long time may achieve desired results in reducing musculoskeletal disorders in small scale and poor industries in developing countries.

Keywords: Developing Countries; Intervention Studies; Musculoskeletal Diseases; Mining

\section{Background}

In many countries, small-scale industries are the main providers of new employment. In addition, these industries play an outstanding part in the economic development of countries by producing export products. There is no internationally accepted definition of a small-scale industry and different countries have provided different definitions for such industries. For instance, Germany, Italy and France define small-scale enterprise if it employs fewer than $500 \mathrm{em}$ ployees (1). However, in Iran enterprises, employing fewer than 10 employees is categorized in this group (2).

International labor office (ILO) has provided a worldwide program to help a wide range of industries to improve their working conditions and ergonomics programs are one of them (3). Although ergonomics in developing countries is very essential in efficient use of technology for industrialization, the attention and interest among organiza- tions and industrial leaders in these countries is very low. Lack of awareness of hidden benefits of these programs is one of the main reasons for the low application of the principles of ergonomics. However, there is no doubt that the use of micro-and macro-ergonomics to improve the working conditions, system performance, and improved quality of work life in developing countries is essential (4).

In Iranian industries, like most developing countries, the knowledge of the ergonomics applications that can eliminate the development obstacles and increase the industrial efficiency is very low (4). Due to these reason, musculoskeletal disorders are one of the most important job diseases in this country (2,5-7). Extensive efforts to introduce ergonomics and its benefits to Iranian industries started systematically in several phases, under the auspices of the center for ergonomics of developing countries (CEDC) during 1993

Copyright (C) 2015, Health Promotion Research Center. This is an open-access article distributed under the terms of the Creative Commons Attribution-NonCommercial 4.0 International License (http://creativecommons.org/licenses/by-nc/4.0/) which permits copy and redistribute the material just in noncommercial usages, provided the original work is properly cited. 
to 2003 (8). Due to the researchers' efforts, ergonomics interventions in the Iranian industries gradually expanded. Among these interventions, Choobineh and Helali studies in various industries can be cited $(4,9,10)$.

In March 2012, the management of a mine located in Arak, a central city of Iran considered musculoskeletal disorders in various parts of the body such as low back; after consultation with the supervisor and safety health undertakings of the company, the request for this study was applied. In this mine, lead and zinc are extracted. In this research, due to the poor nature of the industry, engineering interventional method combined with management interventional approach with a low cost was used.

Engineering controls are the first interventional approaches to reduce the risk factors that cause musculoskeletal disorders, such controls that can be noted in workstation, work methods, tools and equipment designs. Administrative controls not only are the second line of defense to reduce the exposure to work-related musculoskeletal disorders (WMSDs) risk factors, but can also be used as a supplement method in addition to engineering controls. Administrative methods such as training, job rotation and exposure time management can be noted. Engineering controls with training is one of the most important interventional approaches to reduce the exposure to WMSDs risk factors (11-13).

Mining jobs are such that workers are exposed to numerous ergonomic risk factors such as poor postures, use of improper tools, and excessive force in different parts of the body $(14,15)$. Such risk factors in this occupational group have led to many problems for them. For example, studies have shown that the mining industry had the second highest incidence ratio for low back disorders (1.5 claims/100 workers), trailing only to the construction industry (1.6 claims/100 workers)(14). Therefore, evaluating these jobs with the purpose of design and implementation of appropriate ergonomic interventions for improving their working conditions seems to be necessary.

\section{Objectives}

The aim of this study was to provide simple, practical and effective control strategies, to reduce the workers' exposure to WMSDs risk factors among the employees of a lead mine.

\section{Patients and Methods}

This follow-up and interventional study was carried out in a lead mine located in Markazi Province with 50 employees. Twenty five persons were in the flotation unit, 15 worked in the pharmacy unit, and 10 were security and administrative personnel. The initial evaluation of the lead mine based on the interviews and safety and health department documentation indicated that the most common complaints were in pharmacy and flotation units and security and administrative personnel had proper states. As a result, administrative and maintenance staff were excluded. Subsequently, in this research, all the per- sonnel who worked eight hours in flotation and pharmacy units were engaged in this study. The study flow chart is presented in Figure 1. Before the study, all the participants filled out and signed informed consents. The main task of the people employed in the flotation unit was machines and ponds supervising. These people were responsible for checking the operation of the machines while shoveling the tanks and ponds and may face with risk factors such as long-time standing and improper postures while working. Pharmacy is a unit to which bags of chemicals required for lead and zinc extraction are transported and emptied in a hole which is the input mixer. These people are also exposed to risk factors such as awkward postures during carrying load and excessive force. At the first step, a meeting with the management team of the company was formed, and regarding the purpose of this study and its benefits such as creation of proper ergonomic condition with the purpose of job satisfaction and higher productivity, the conversations were conducted. A participatory ergonomics approach was initiated through an ergonomic committee after the management team's commitment for supporting this research (16). The ergonomic committee involved the management, workers' representatives, health and safety engineers and researchers. The current problems reviewed by the committee members to select appropriate methods of assessment and intervention were discussed. Due to the poor nature of the industry and the management recommendations for achieving success to reduce musculoskeletal disorders, easy and low cost (the most important factor) methods were used. Finally, three phases including initial evaluation, intervention, and assessing the effectiveness of interventions phases were planned and carried out.

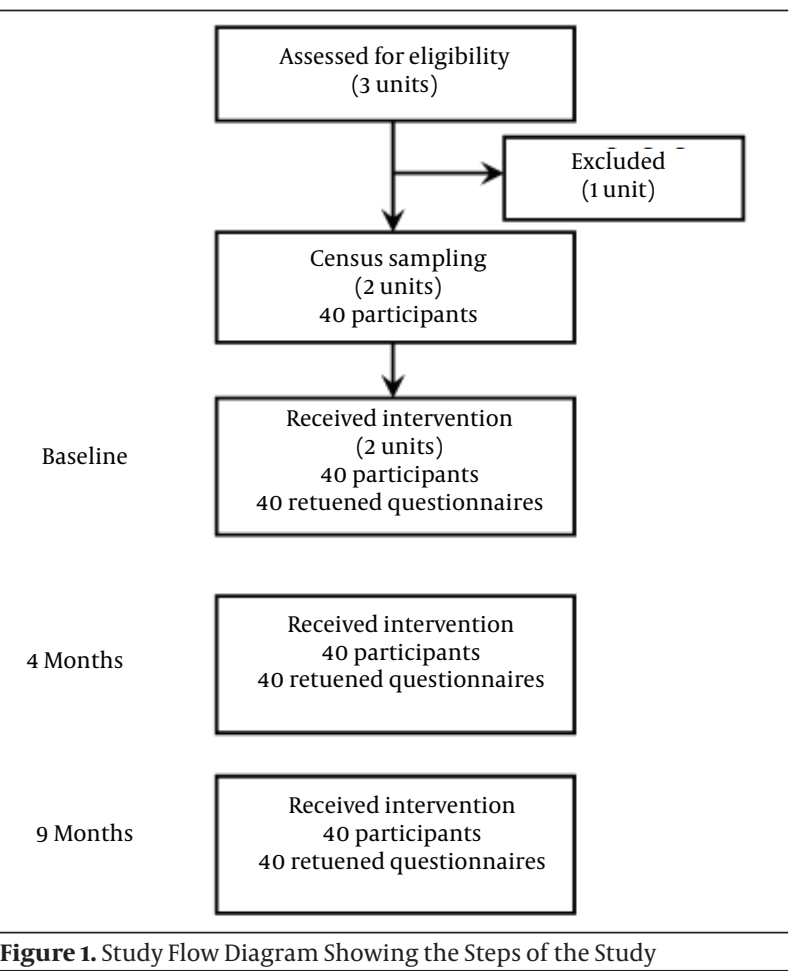




\subsection{Phase I; Preliminary Work Evaluation}

A) Data were collected via nameless questionnaires such as Persian version of general nordic musculoskeletal questionnaire (NMQ) to examine the reported cases of WMSDs among the study population. Reported WMSDS symptoms were limited to the 12 months prior to the study. The questionnaires were completed on the basis of an interview with each worker (17). Demographic characteristics such as age and work experience of employees were added in the questionnaire.

B) The evaluation of ergonomic risk factors that cause musculoskeletal disorders and risk levels determination in the subjects were conducted. For this purpose, the standard method of quick exposure check (QEC) was used. QEC is a pen and paper observational method developed firstly by Li and Buckle in 1998 and enhanced by David et al. in 2003 (cited in David et al. (18)). QEC analysis produces scores for the back, shoulder/arm, wrist/ hand, and neck, regarding their positions and repetitive movements. In QEC, the task duration, maximum weight handled, hand force exertions, vibration, visual demand of the task and subjective responses to work are also calculated, whereas the essential data are obtained from the worker. In QEC, to achieve an overall score, the total scores obtained from four body parts are added and the product is divided by the maximum possible score, i.e., 176 for manual material handling tasks and 162 for others. Low scores $(<40 \%$ ) indicate satisfactory loading (low risk). For $41 \%$ to $50 \%$, further investigation is needed and changes may be required (moderate risk). Timely investigation and changes are required soon for scores of 51\% to $70 \%$ (high risk); crucial exploration and changes are required for scores over 70\% (very high risk). Finally, QEC offers four categories for estimating the risk level. These risk levels named from 1 to 4 are corresponding to low, moderate, high and very high risk level, respectively (18). After the investigation of the prevalence of musculoskeletal disorders and determining the risk levels of the tasks, appropriate interventions were implemented.

\subsection{Phase II; Interventions}

Due to the most current important risk factors such as improper lifting methods, poor staff awareness of how to properly do the job, standing for a long time (flotation units), manually lifting excessive loads (40 kg) and inappropriate workstation conditions (high input mixer) in this research, engineering and administrative control methods were used together to intervene the tasks. After reviewing various methods, simple and low-cost interventions were selected as follows:

1- Theoretical and practical workshops and face-to-face training during work. The content of the training included: training workers and supervisors about the correct and incorrect working postures, correct lifting and carrying, training stretch exercises for preventing musculoskeletal disorders. 2- Job rotation between the two units were studied to reduce the monotony of work, increased necessary time for muscle recovery after lifting heavy loads and preventing muscular strain, low back pain, repetitive strain, excessive fatigue. 3- Changing the sizes of transported objects (minimize the size of the bags containing chemicals for extraction of zinc and lead. 4- Changes in weight of the objects transported (decreasing the weight of bags from $40 \mathrm{~kg}$ to less than $20 \mathrm{~kg}$ according to the recommended limits in psychophysical tables (19). 5- Increasing the height of the unloading bags in the entrance of the mixer from $40 \mathrm{~cm}$ to $90 \mathrm{~cm}$ (adjusting the work surface to elbow height or a little below that). All these solutions were chosen from the ergonomics checkpoint provided by the international labor organization (ILO) (3).

\subsection{Phase III; Evaluation of the Effectiveness of Interventions}

At four and nine months after the interventions, the risk factors that cause musculoskeletal disorders and the prevalence of musculoskeletal disorders were evaluated again via QEC method and Nordic questionnaire, respectively, and the effectiveness of ergonomics interventions were determined and compared with the previous data. Statistical analyses were performed using SPSS version 11. McNamar's and Cochran's tests were used to compare the groups before and after the intervention in terms of musculoskeletal symptoms.

\section{Results}

Table 1 summarizes the personal details and demographics of the employees participating in the study. The result of the risk assessment of ergonomics risk factors using QEC before and after the intervention is presented in Table 2. As seen, most of the workers in the phase before the interventions were in risk level 3; but after the intervention, the risk level improved.

Table 3 presents the prevalence of musculoskeletal disorders before and after the ergonomics interventions in different body regions during the 12 months prior to the study. The results revealed that the highest rates of WMSDs were in the lower back (57.5\%), knees (50\%), neck(30\%), shoulders (27.5\%), and wrists (25\%). These disorders in lower back, shoulders, hand wrists and knees decreased after four months of follow-up, but this reduction was not significant according to McNamar's test. Nine months after the intervention, the results showed a greater reduction in the incidence of WMSDs in various body regions. According to McNamar's test, most of the decline was in the lower back region $(P=0.002)$. In addition, the reduction of WMSDS in knees was significant according to McNamar's test after the lower back decline ( $\mathrm{P}$ $=0.008)$. The reduction in discomfort in different areas of the body in prior, four and nine months after the interventions in different regions, such as shoulders, wrists, lower back and knee indicated significant differences according to Cochran's test. Most of the decline was observed in lower $\operatorname{back}(\mathrm{P}=0.001)$ and then in the knee $(\mathrm{P}=0.002)$. 
Jahangiri M et al.

Table 1. Individual Data and Demographics of the Employees Participated in the Study

\begin{tabular}{|c|c|c|c|c|}
\hline Action Groups & No. & Values $^{\mathrm{a}}$ & Minimum & Maximum \\
\hline \multicolumn{5}{|l|}{ Pharmacy, y } \\
\hline Age & 15 & $35.4 \pm 2.1$ & 32.0 & 39.0 \\
\hline Job tenure & 15 & $4.9 \pm 1.4$ & 3.0 & 7.0 \\
\hline \multicolumn{5}{|l|}{ Flotation, y } \\
\hline Age & 25 & $35.1 \pm 2.5$ & 31.0 & 40.0 \\
\hline Job tenure & 25 & $4.3 \pm 1.7$ & 2.0 & 8.0 \\
\hline \multicolumn{5}{|l|}{ Total, y } \\
\hline Age & 40 & $35.2 \pm 2.3$ & 31.0 & 40.0 \\
\hline Job tenure & 40 & $4.5 \pm 1.6$ & 2.0 & 8.0 \\
\hline
\end{tabular}

${ }^{a}$ Data are presented as mean $\pm S D$.

\begin{tabular}{|c|c|c|c|}
\hline \multirow{2}{*}{ QEC Levels } & \multicolumn{2}{|c|}{ Job Groups } & \multirow{2}{*}{ Total } \\
\hline & Flotation Unit & Pharmacy & \\
\hline \multicolumn{4}{|c|}{ Before Interventions } \\
\hline Level 1 & - & - & - \\
\hline Level 2 & $6(15)$ & - & $6(15)$ \\
\hline Level 3 & $19(47)$ & $11(27)$ & $30(75)$ \\
\hline Level 4 & - & $4(10)$ & $4(10)$ \\
\hline \multicolumn{4}{|c|}{ After interventions } \\
\hline Level 1 & - & - & - \\
\hline Level 2 & $15(37.5)$ & $25(62.5)$ & $40(100)$ \\
\hline Level 3 & - & - & - \\
\hline Level 4 & - & - & - \\
\hline
\end{tabular}

${ }^{a}$ Values are presented as No. (\%).

Table 3. The Prevalence of Musculoskeletal Disorders Before, Four and Nine Months After the Intervention ${ }^{a}$

\begin{tabular}{|c|c|c|c|c|c|c|}
\hline Body Region & $\begin{array}{c}\text { Before } \\
\text { Interventions }\end{array}$ & $\begin{array}{l}\text { Four Months After } \\
\text { Interventions }\end{array}$ & $\begin{array}{l}\text { Nine Months After } \\
\text { Interventions }\end{array}$ & PValue $^{\mathrm{b}}$ & PValue $^{\mathrm{C}}$ & PValue $^{\mathrm{d}}$ \\
\hline Neck & $12(30)$ & $13(32.5)$ & $9(22.5)$ & 1 & 0.25 & 0.39 \\
\hline Shoulder & $11(27.5)$ & $9(22.5)$ & $6(15)$ & 0.5 & 0.062 & 0.022 \\
\hline Elbow & $3(7.5)$ & $3(7.5)$ & $2(5)$ & 1 & 1 & 0.717 \\
\hline Wrist & $10(25)$ & $7(17.5)$ & $5(12.5)$ & 0.25 & 0.062 & 0.022 \\
\hline Lower back & $23(57.5)$ & $21(52.5)$ & $13(32.5)$ & 0.5 & 0.002 & 0.001 \\
\hline Hip & $8(20)$ & $6(15)$ & $6(15)$ & 0.5 & 0.5 & 0.135 \\
\hline Knee & $20(50)$ & $16(40)$ & $12(30)$ & 0.125 & 0.008 & 0.002 \\
\hline Foot & $6(15)$ & $6(15)$ & $5(12.5)$ & 1 & 1 & 0.368 \\
\hline
\end{tabular}

${ }^{a}$ Values are presented as No. (\%)

b McNamar's test with a 95\% confidence interval of discomfort between before and four months after the interventions.

c McNamar's test with a 95\% confidence interval of discomfort between before and nine months after the interventions.

$\mathrm{d}$ Cochran's test with a $95 \%$ confidence interval of discomfort between before, four and nine months after the interventions. 


\section{Discussion}

The results of the riskassessment factors causing musculoskeletal disorders showed that after the interventions, the risk levels determined by the QEC method decreased from levels 3 and 4 to level 2 . This would represent the relative improvement in the ergonomic situation of the employees in the present study. The implementation of ergonomic interventions in this study could improve the working postures, appropriate judgment about the applied force to the body, and the Satisfaction of load weigh and reduce the work frequency, and ultimately lead to a reduction in the final risk levels by the QEC method.

The results of the prevalence of musculoskeletal disorders showed that the disorders in knees, back, shoulders and wrists significantly decreased in the time of follow-up. These findings represented the importance of the implementation of ergonomics, engineering and management interventions simultaneously, leading to a significant disorders reduction in those areas. The lack of primary management attention to the ergonomics problems of work environments as well as the insufficient knowledge of ergonomics managers, supervisors and workers of the basic issues of ergonomics, caused an increase in workers' musculoskeletal disorders in this study. As was shown after the interventions, these disorders somewhat decreased, which would suggest that these interventions can reduce such disorders in employees. It should also be considered that the interventions used in this study were the least actions that could be performed in a working environment due to the existing restrictions in the industry such as the poor industry, and therefore these interventions could not be considered as complete actions to reduce musculoskeletal disorders. Although simple and low-cost methods were used in this study, a significant decrease was shown in musculoskeletal disorders in some organs.

The most important reason that makes these interventions effective was a combined use of engineering and management techniques during a long period. Because of this approach, the most important and effective action is to improve the ergonomics situation of the working environment (20-22). Besides, the management's commitment and the collaboration of workers and supervisors can be another reason for the effectiveness of these interventions (16). The achieved results in this study are in accordance with other studies indicating that ergonomics interventions reduce musculoskeletal disorders.

In a study by Choobineh et al. on the staff working in an oil refinery, educational interventions as well as improvement in the working environment such as purchasing ergonomic chairs, improving the existing seats, adjusting the height of keyboard and monitor according to the characteristics of each person and the use of a wrist support for the administration staff were applied. Repeating these assessments six months after the start point of specific interventions application showed a significant reduction of musculoskeletal disorders in parts of back, lower back, ankle and foot in the intervention group compared to the control group (9).

One of the most important results of the present study was reviewing the effectiveness of interventions in two different periods. In the first phase (four months after the intervention), despite the reduction in the prevalence of some of the disorders, none of them were meaningful with respect to McNamar's statistical test. However, checking again nine months after the start of the interventions, a remarkable disorder reduction in the lower back, knees, shoulders and wrists were shown; these reductions in the back and knees in terms of statistics were more meaningful.

Besides assessing the concurrent disorders in the areas reviewed in previous interventions, four and nine months after the start of interventions, significant disorders reductions in the shoulders, wrists, back and knees were shown. This reduction rate according to Cochran's test was significant. The reason behind this issue can be somewhat related to the nature of the creation of these disorders. As known, if there is an inappropriate ergonomic condition in the workplace, disorders can be caused gradually, and therefore, if the environmental ergonomics condition improves through appropriate and effective interventions, the disorders recovery will also require the passage of time (23).

In the present study, although the assessment before the interventions showed inappropriate ergonomics conditions in the workplace, the commitment and support of manager and the Partnership of workers, as well as the use of the least engineering and administrative interventions led to the improvement of the ergonomics situation compared to the time before the implementation of interventions. The correct implementation of these interventions and continuous monitoring in a long period of time led to a significant disorder reduction in nine months, although the reduction was not that significant after four months.

One of the results of this study was increase of neck pain after four months of intervention (increase in one person) and its reduction over the nine months of intervention (reduction in four people). It seems that the most important achievement of these results may be consistent with the low sample size in this study, because this sample size may not reflect the change of the prevalence of musculoskeletal disorders such as neck pain.

Other points could be discussed in the present study is the concomitant use of engineering and management interventions. In this respect, some studies at the international level and in particular in developing countries have been conducted, which applied the simultaneous use of these methods for improving the ergonomics of working environments. For example, in a study that Helali and associates conducted in one of Iranian industries, 
using concurrent engineering and management control such as holding multiple ergonomics training courses for workers, supervisors and managers, improving lighting and ventilation of the working environment, appropriate design of workstations, using the appropriate tools and chairs and reducing the load weight, they were able to improve the ergonomic situation in the studied factory (10).

The Benefits of this study would be the simultaneous application of these methods and the simple design of the interventions as well as the use of low-cost and effective interventions. Its proper effectiveness is also the strengths of this study. One of the most important restrictions in this study was gathering information in the form of self-reporting (Nordic questionnaire). This method may have had negative effects on the study (9). Justifying the managers and staff to cooperate in the study, economic restrictions in design and selection of interventions, the long time needed for this research and continuous monitoring can be mentioned as other restrictions.

Finally, according to the results of this study, it can be understood that in developing countries, by increasing the knowledge of managers, supervisors, and employees as well as applying the correct principles of ergonomics, using simultaneous basic, simple and cheap engineering, and management controls, the musculoskeletal disorders would reduce. This should also be considered that the participation of employees as well as the managers' support and commitment seems essential in achieving the desirable results in using intervention methods.

\section{Acknowledgements}

Researchers are grateful to the managers of the factory due to the financial and spiritual support; they also express sincere thanks to the mine workers due to their cooperation and partnership in this research. Sincere gratitude goes to Mr. Yavari, the health professional expert of the company, due to his continuous monitoring and cooperation.

\section{Authors' Contributions}

Mohammad Jahangiri and Abbas Jahangiri contributed in doing the study and implementation and monitoring interventions, Tahere Gholami translated Persian version to English, Hassan Mohammadpour and Ghasem Hesam contributed in data collection, Mahdi Jalali designed the study, analyzed the results and wrote the primary draft of this manuscript as a supervisor and corresponding author, Seyyed Ali Moussavi Najarkola revised the draft manuscript and doing the data quality control.

\section{References}

1. Reverente BR. Occupational health services for small-scale industries. In: Jearatnam J, editor. Occupational health in developing countries. Oxford: Oxford University Press; 1992. pp. 62-88.
2. Choobineh A, Shahnavaz H, Lahmi M. Major health risk factors in Iranian hand-woven carpet industry. Int J Occup Saf Ergon. 2004;10(1):65-78.

3. International Labour Office International Ergonomics Association. Ergonomic Checkpoints: Practical and easy-to-implement solutions for improving safety, health and working conditions. 2 ed. Geneva: ILO Press; 2010. pp. 1-298.

4. Helali F, Shahnavaz H. Ergonomics intervention in industries of the industrially developing countries. Case study: GlucosanIran. Hum factors Organ Des Manag . 1996:141-6.

5. Choobineh A, Tabatabaee SH, Behzadi M. Musculoskeletal problems among workers of an Iranian sugar-producing factory. Int $J$ Occup SafErgon. 2009;15(4):419-24.

6. Choobineh A, Tabatabaei SH, Mokhtarzadeh A, Salehi M. Musculoskeletal problems among workers of an Iranian rubber factory. JOccup Health. 2007;49(5):418-23.

7. Choobineh A, Tabatabaei SH, Tozihian M, Ghadami F. Musculoskeletal problems among workers of an Iranian communication company. Indian J Occup Environ Med. 2007;11(1):32-6.

8. Helali F, Shahnavaz H, editors. A macroergonomics approach, a journey into system thinking Ergonomics Intervention Programme (EIP) in industrially developing countries (IDC), Case IRAN 1993-2003.; Proceedings of the XVth Triennial Congress of the International Ergonomics Association and the 7th Joint Conference of Ergonomics Society of Korea/Japan Ergonomics Society. Seoul, Korea: Ergonomics Society of Korea.; 2003; Korea. pp. 118-21.

9. Choobineh A, Motamedzade M, Kazemi M, Moghimbeigi A, Heidari Pahlavian A. The impact of ergonomics intervention on psychosocial factors and musculoskeletal symptoms among office workers. Int J Ind Ergon. 2011;41(6):671-6.

10. Helali F, Lonnroth EC, Shahnavaz H. Participatory ergonomics intervention in an industrially developing country--a case study. Int J Occup Saf Ergon. 2008;14(2):159-76.

11. Pillastrini P, Mugnai R, Farneti C, Bertozzi L, Bonfiglioli R, Curti $\mathrm{S}$, et al. Evaluation of Two Preventive Interventions for Reducing Musculoskeletal Complaints in Operators of Video Display Terminals. Phys Ther. 2007;87(5):536-44.

12. Poosanthanasarn N, Lohachit C, Fungladda W, Sriboorapa S, Pulkate C. An ergonomics intervention program to prevent worker injuries in a metal autoparts factory. Southeast Asian J Trop Med Public Health. 2005;36(2):512-22.

13. Amick B3, Robertson MM, DeRango K, Bazzani L, Moore A, Rooney $\mathrm{T}$, et al. Effect of office ergonomics intervention on reducing musculoskeletal symptoms. Spine (Phila Pa 1976). 2003;28(24):2706-11.

14. Bandyopadhyay A, Dev S, Gangopadhyay S. A Study on the Prevalence of Musculoskeletal Disorders among the Coalminers of Eastern Coalfields of India. Int J Occup Saf Health. 2012;2(2):34-7.

15. Punnett L, Wegman DH. Work-related musculoskeletal disorders: the epidemiologic evidence and the debate. J Electromyogr Kinesiol. 2004;14(1):13-23.

16. Rosecrance JC, Cook TM. The use of participatory action research and ergonomics in the prevention of work-related musculoskeletal disorders in the newspaper industry. Appl Occup Environ Hyg. 2000;15(3):255-62.

17. Kuorinka I, Jonsson B, Kilbom A, Vinterberg H, Biering-Sørensen F, Andersson G, et al. Standardised Nordic questionnaires for the analysis of musculoskeletal symptoms. Appl Ergon. 1987;18(3):233-7.

18. David G, Woods V, Li G, Buckle P. The development of the Quick Exposure Check (QEC) for assessing exposure to risk factors for work-related musculoskeletal disorders. Appl Ergon. 2008;39(1):57-69.

19. Snook SH, Ciriello VM. The design of manual handling tasks: revised tables of maximum acceptable weights and forces. Ergonomics. 1991;34(9):1197-213.

20. Deeb JM. Administrative controls as an ergonomic intervention. In: Karwowski W, Marras WS, editors. Fundamentals and assessment tools for occupational ergonomics- intervantions, controls, and applicationsin occupationals ergonomics-the occupational ergonomics handbook. London: Taylor \& Francis; 2006. pp. 366-73.

21. Hales TBP. Medical management of work-related musculoskel- 


\section{Jahangiri M et al.}

etal disorders. In: Marras WS, Karwowski W, editors. Interventions, controls, and applications in occupational ergonomics. 2 ed. London: Taylor \& Francis; 2006. pp. 522-8.

22. Winkelstein BA. Mechanisms for pain and Injury in musculoskeletal disorders. In: Marras WS, Karwowski W, editors. Fundamental and assessment tools for occupational ergonomics. 2 ed. London:
Taylor \& Francis; 2006. pp. 406-7..

23. Aaras A, Horgen G, Bjørset HH, Ro O, Walsoe H. Musculoskeletal, visual and psychosocial stress in VDU operators before and after multidisciplinary ergonomic interventions. A 6 years prospective study-Part II. Appl Ergon. 2001;32(6):559-71. 